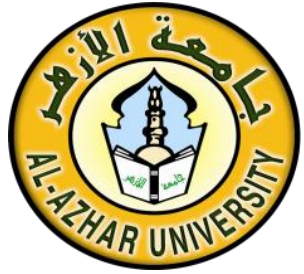

\author{
جامعة الأزهر \\ كلية الدراسات الإسلامية و العربية

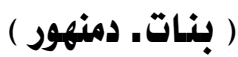

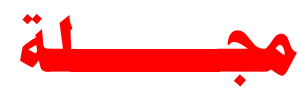

كلية الدراسات الإسلاهية و العربية

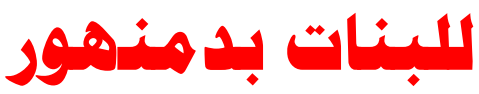

مجلة علمية محكمة لنشر البحوث الإسلامية والعربية والقانونية

$$
\begin{aligned}
& \text { العدد الخامس - الإصدار الثاني } \\
& \text { الجزيء الثامن } \\
& \text { A r.r./AISEY }
\end{aligned}
$$

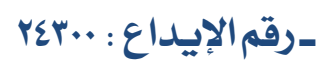

ـ الترقيم الدولي : 0962 - ISSN 2357

Email : hebasayedhh@gmail.com : البريد الإلكتروني

ـ الموقع الإلكتروني: http://jcia.journals.ekb.eg

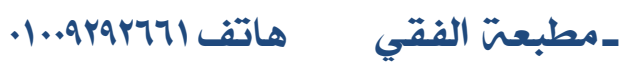

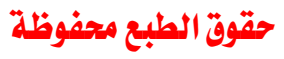
كلية الدراسات الإسلامية والعربية للبنات بلدمنهور 


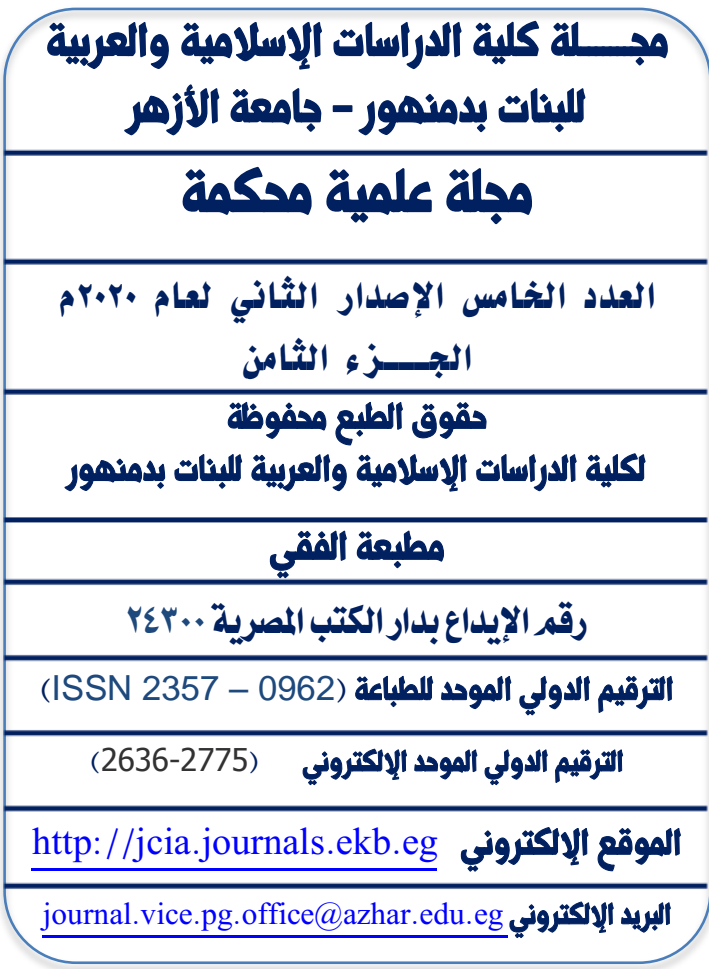




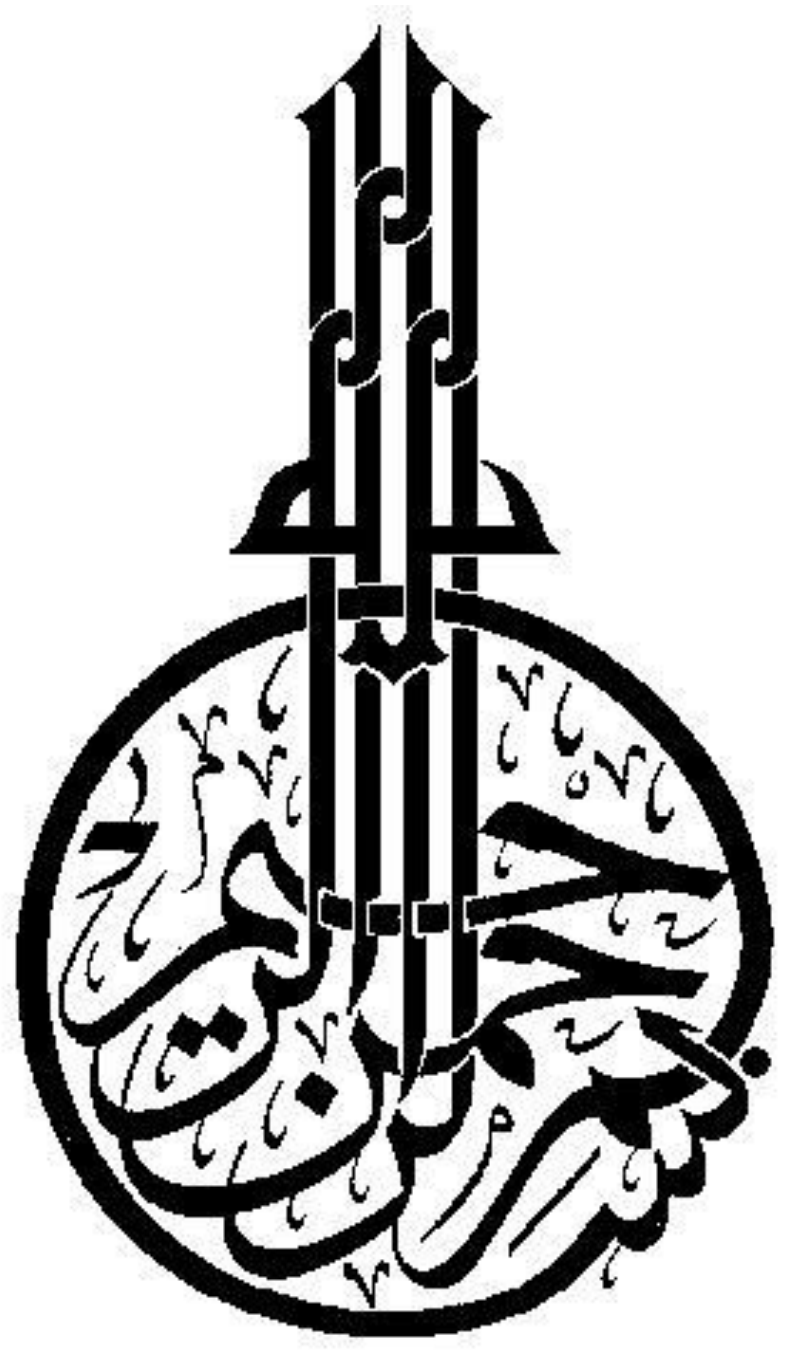




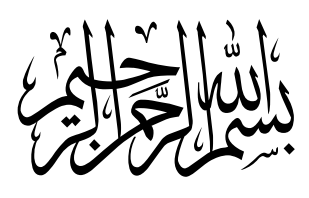

\section{كلمة العدد}

الحمد لله الذي بنعمته تتم الصالحات ، و الصـلاة و السلام على خيــر

البرية ومعلم البشرية سيدنا محمد بن عبد الله ، و على آله وصحبه ، ومن وله وله اهتذى بهديه وسار على منهجه إلى يوم الدين.

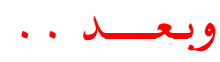

فهذا هو العدد الخامس من المجلة العلمية لكلية الدراسات الإسلامية

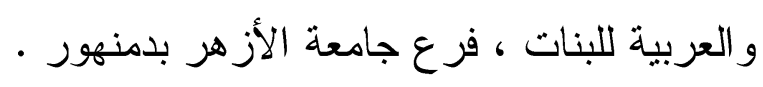

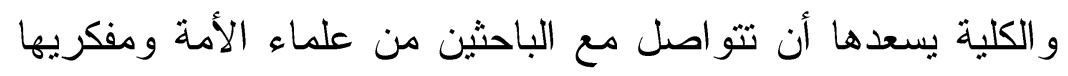

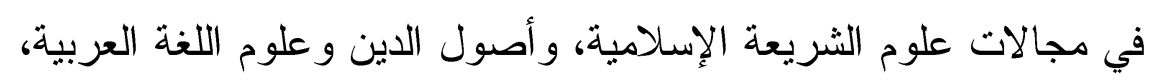
و الدراسات القانونية و الهدف من المجلة تتمثل في الآتي :-

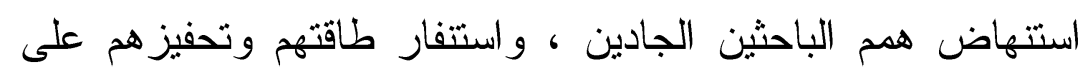

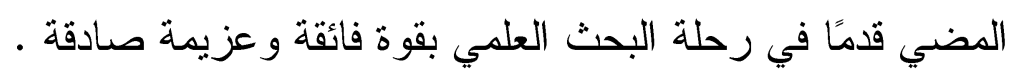

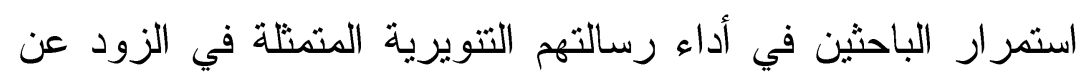
تز اثهم العقدي وكيفية الوصول للحقائق العلمية . 


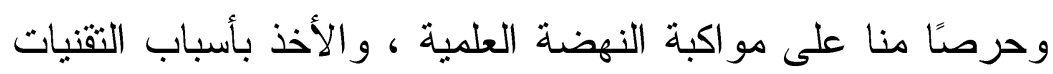

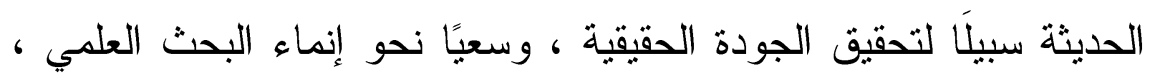
وبناء عقلية بحثية متميزة .

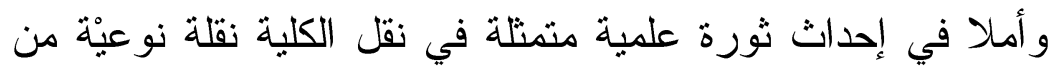

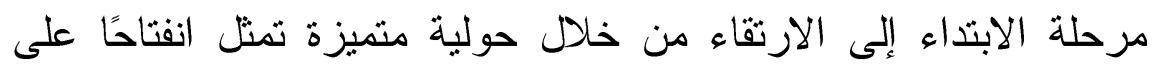

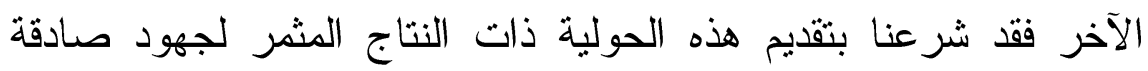
ومنضافرة .

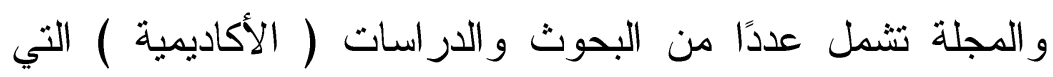

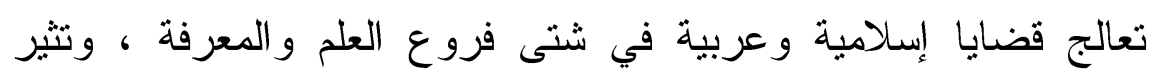

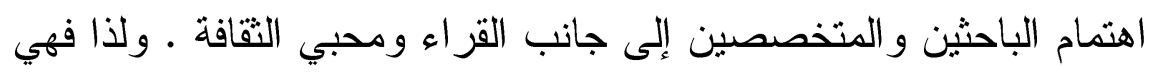

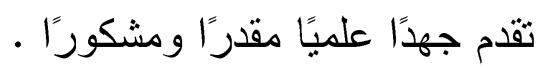

وفي الختام أتوجه بكل الثكر و التقدير إلى جميع السادة الباحثين

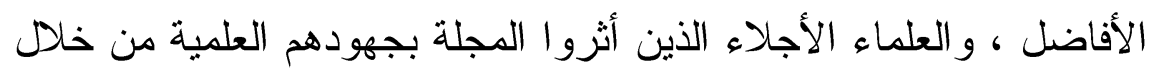

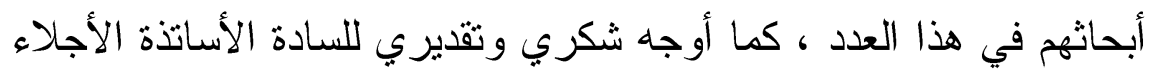

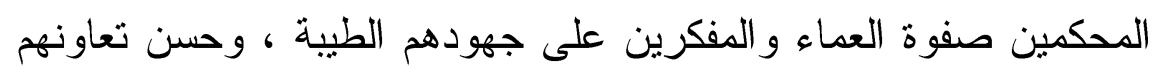

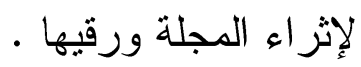

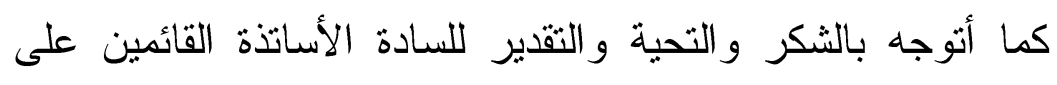

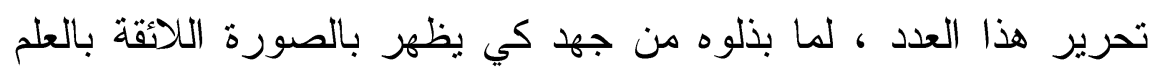
و العلماء. - تحريز

\section{واللّا الموفق ،6، ،}

أ .د / نادةخميس الحناوي

عميد الكليةورئيس تحرير المجلة 


\section{يؤلة المجلة :}

ـ أن تكون المجلة منارة علمية في البحوث الإسلامية والعربية

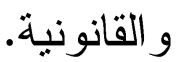

ـ التأسيس من أجل أن يكون للمجلة مكان بارز، وتصنيف رفيع بين أثنر المجلات العلمية المنخصصة في نشر البحوث الإسلامية و العربية و القانونية.

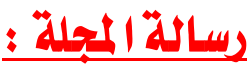

ـ نشر البحوث الإسلامية والعربية و القانونية وفْق أرقى معايير

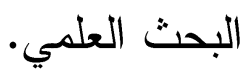

ـ نشر مبادئ وتعاليم سماحة الإسلام الحنيف عبر وسطية الأزهر

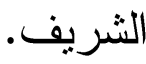

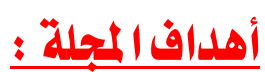

ــ نشر المعرفة الإسلامية و العربية و القانونبة بتحقيق مرجعية علمية متخصصة في هذه المجالات.

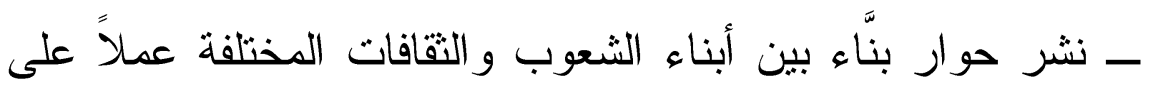
رُقيّيّ وتحضُر جميع بني الإنسانية.

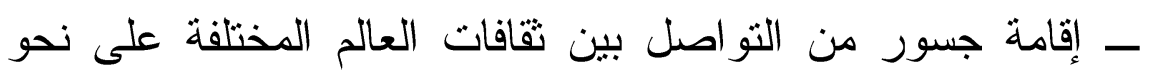
بحدث تفاعلاً إيجابياً تكون فيه علوم الإسلام و اللغة العربية و القانون أعظم الرو افد لتحقيق ذلك. 


\section{تشكيل مجلس الإدارة}

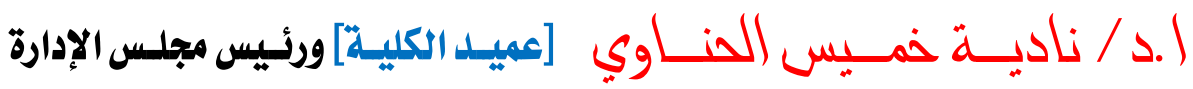
| .د / كمال السيد أحمد العبد [ [وكيل الكلية] ونائب رئيس مجلس الإدارة ( .د / محمــد محمــد الشــواني مثثلاً لتخصص التفسير وعلوم القرآن

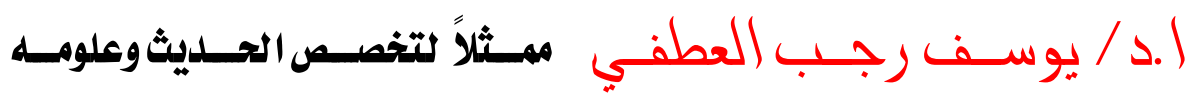

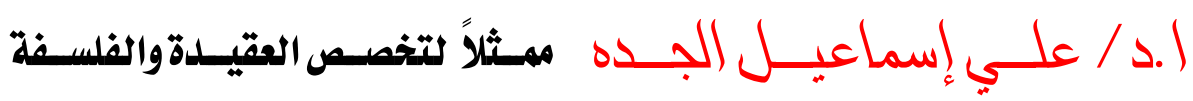

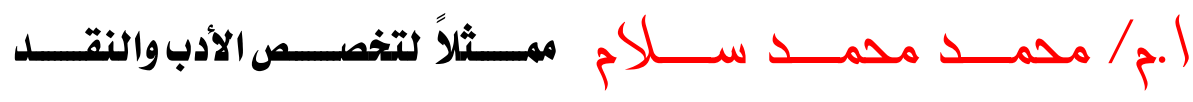

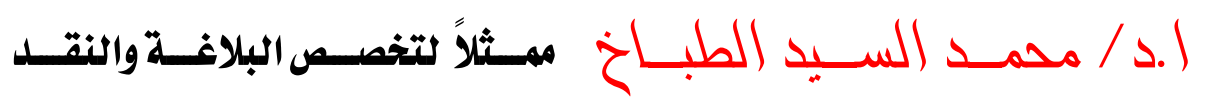

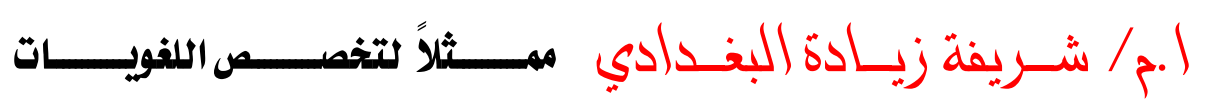

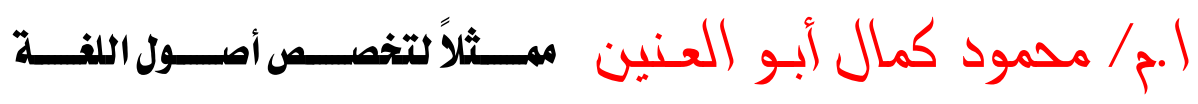

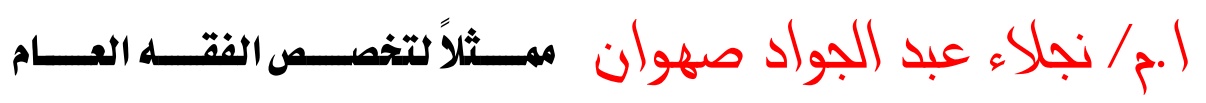

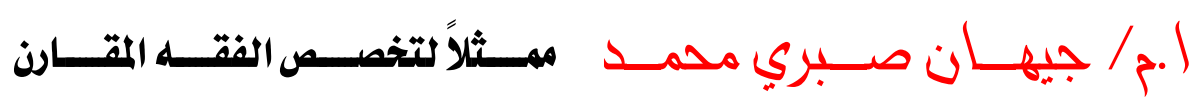

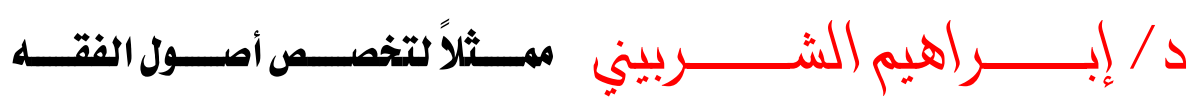

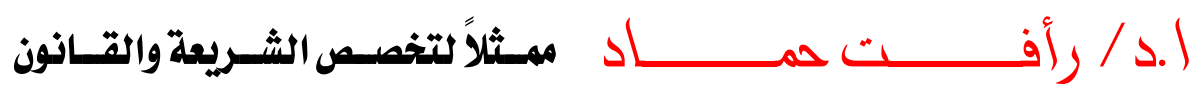




\section{هيئسة التحــريد}

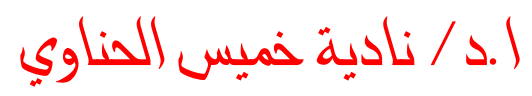

رئيس هيئة التحرير

[عميد الكلية]

I / كمال السيد أحمد العبد

نائب رئيس هيئة التحرير

[وكيل الكلية"شئون التعليم والطلاب]

l. إ / نظير محمد النظير عياد

[ [مضواً وأمين عام مجمع البحوث الإسلامية] مشرفاً عامـاً

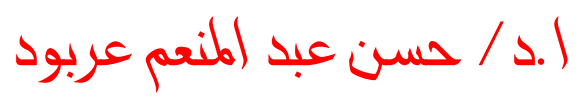

ملير التحرير

[عضوا]

د/ أحمد محمد جبر

مشرفاً تنفيليًاً

[عضوً]

I.د / عادل الصاوي محمود الصاوي

منسقاً تنفيلياً

[عضوً]

/ - هبة سيد عبد الغنى

مسئول إداري و مالي

[عضوا] 


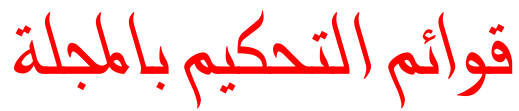

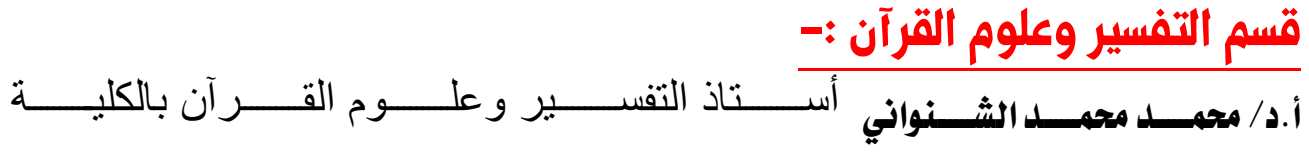

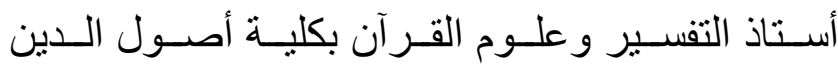

أ.د/ ســــــــــــــــــلال أستاذ التفسير و علوم القرآن بكلية القرآن الكريم بطنطا

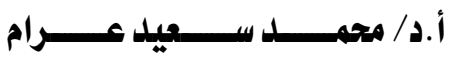

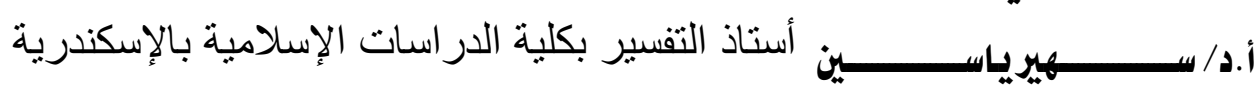

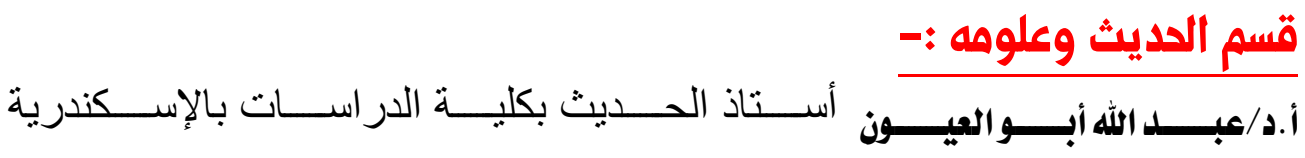

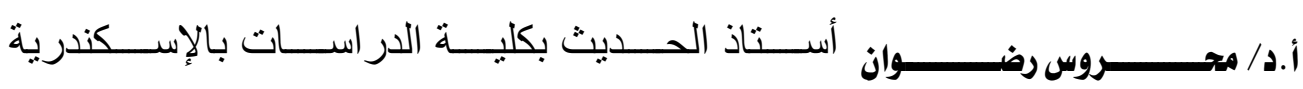

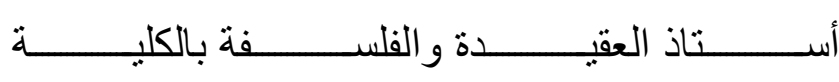
قسم العقيدة والفلسفة :- العبدان

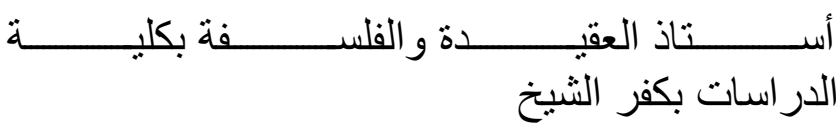

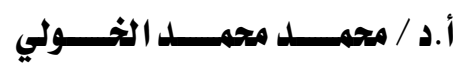

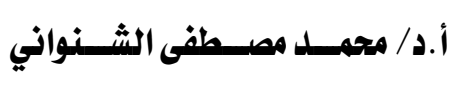

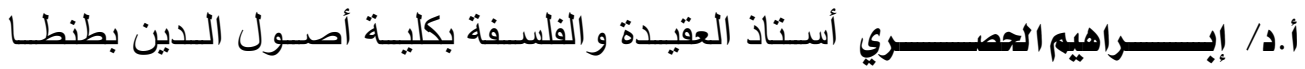

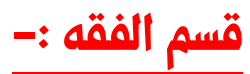

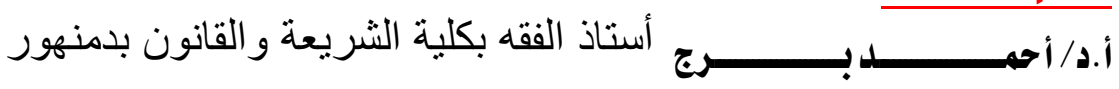

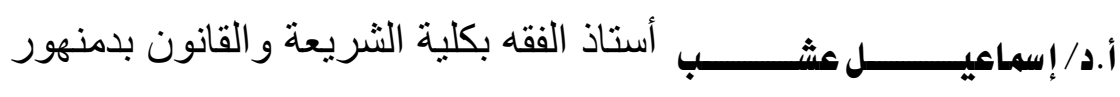

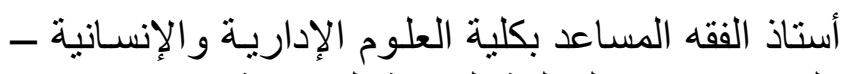
كليات بريدة - المملكة العربية السعودية الإدية

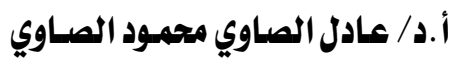

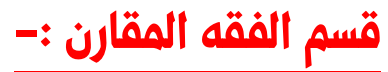

أستاذ الفقه المقارن بكلية الدراسات بدسوق

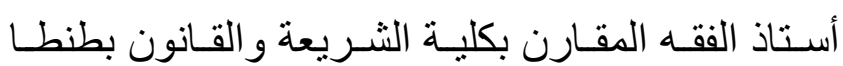
و عضو اللجنة العلمية الدائمة أستاذ الفقه المقارن بكلية الثريعة و القانون بتفهنا الأشر اف أ. أد/ السيد حافظ خليل السخاوي 
قـم أصول الفمه :-

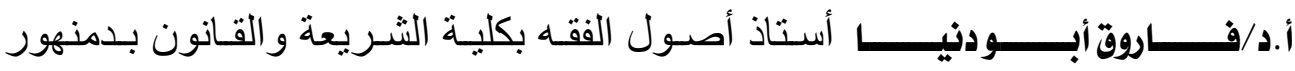

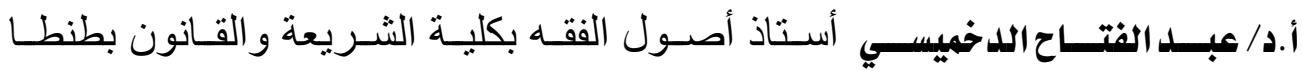

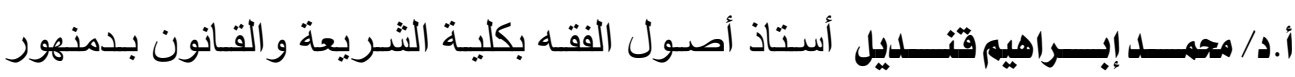

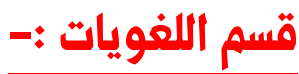

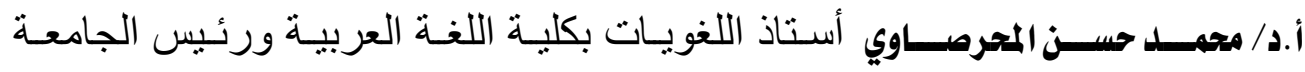

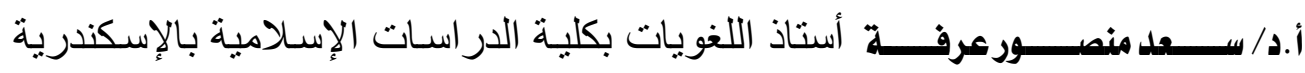

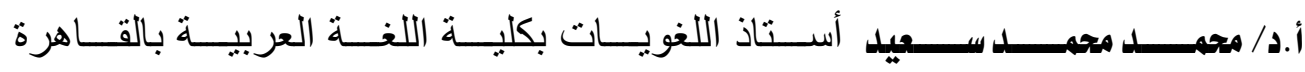

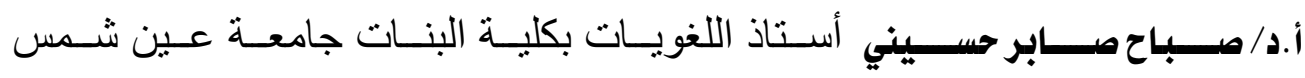

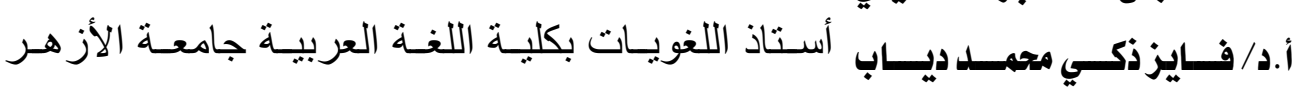

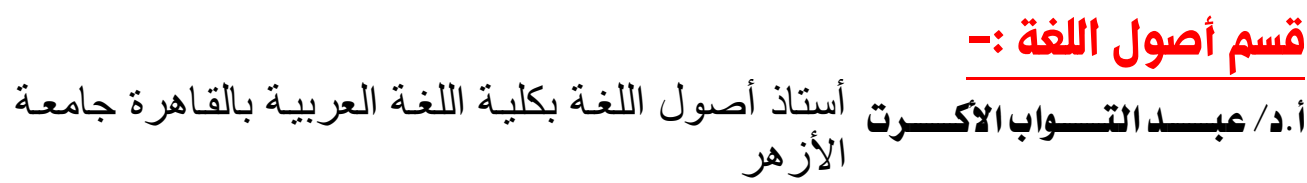
أ.د/ إبراهيه عبدا الحميد أبو سكين أسـتاذ أصــول اللغــة بكليـة اللغــة العربيــة بالقـاهرة

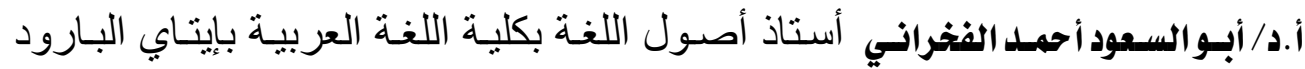

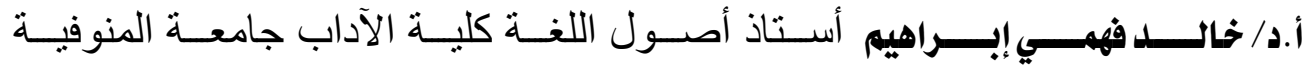

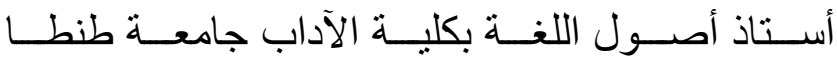

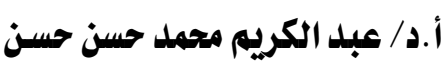
أستاذ أصول اللغـة بكليـة الدر اسـات الإسـلامية بالقاهرة أ. أد/ عبــــ الفتــاح أبــو الفتــوح إبراهيي

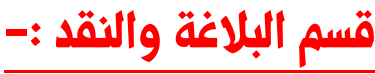

أستاذ البلاغة و النقد بكلية اللغة العربية بالقاهرة ورئيس الجايس

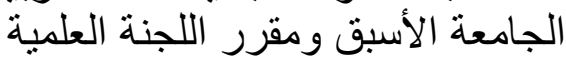
أ أ.د/ إبراهيم صلاح السيد الهدهد أستاذ البلاغة بكلية اللغـة العربيـة بالقاهرة و عميد كليـة

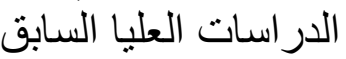
أ. دا مبـل الله عبـد الفني سـرحان

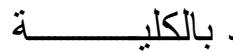

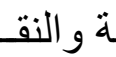

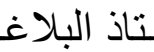

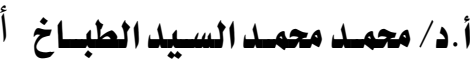

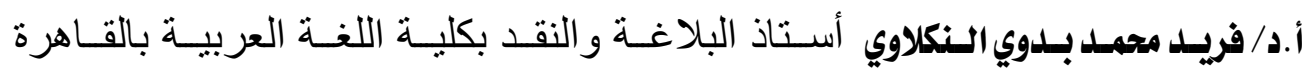




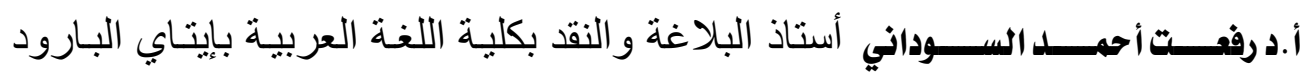

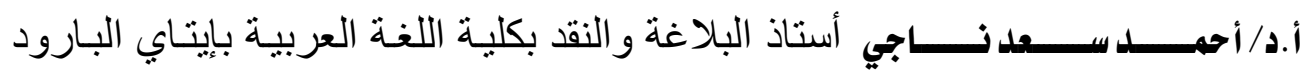

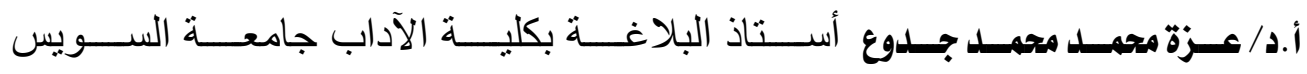

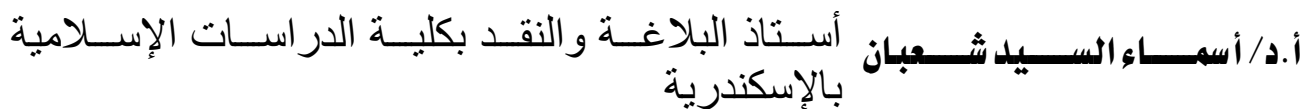
كليـة الآداب الأردنيـة ومجمــع اللغــة العربيـة الأردنيـة عمان المملكة الأردنية الهاشية الأبية

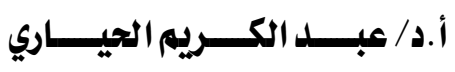

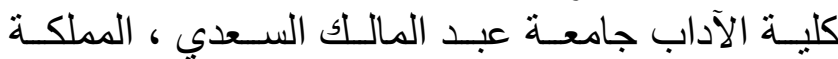

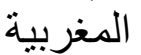

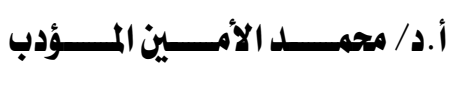

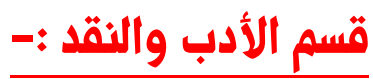

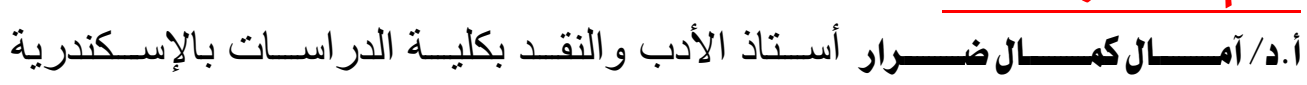

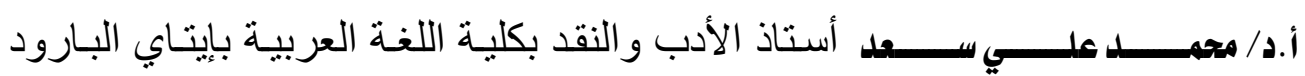

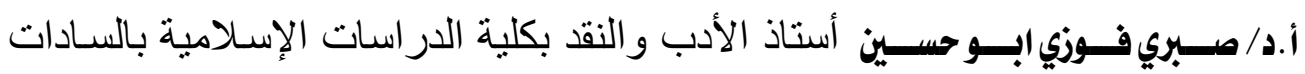

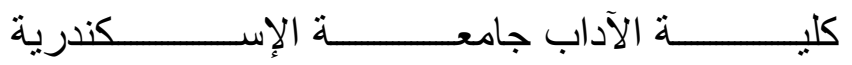

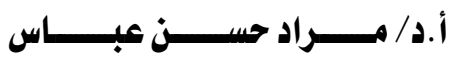

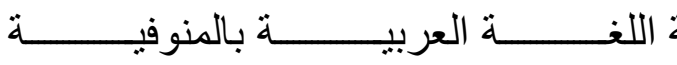
أ. أد/ محمد كـاظم علي الظواهري كلي.

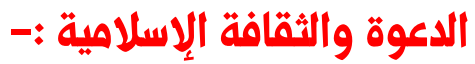

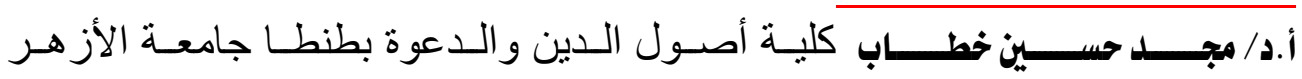

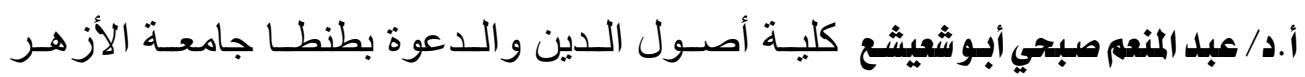

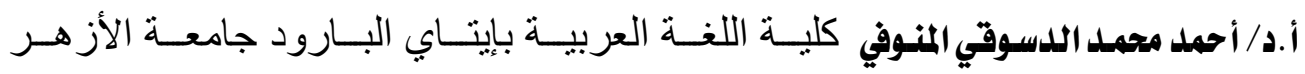

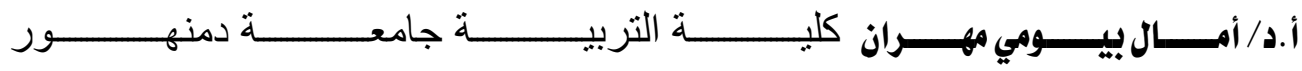

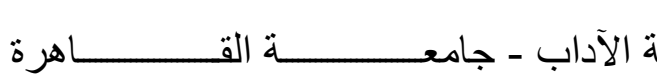
كلي.

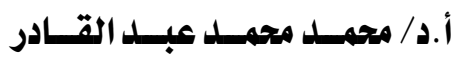
الخطيب

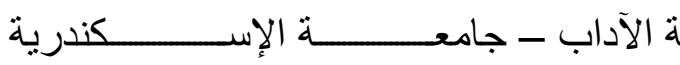

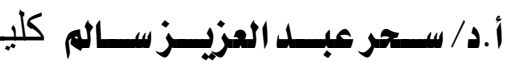

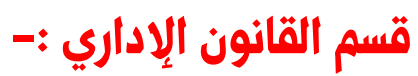

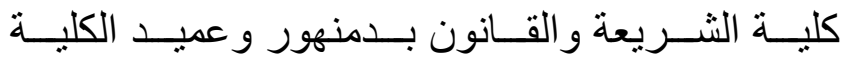

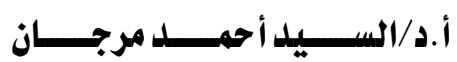

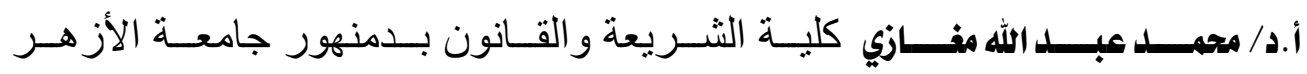

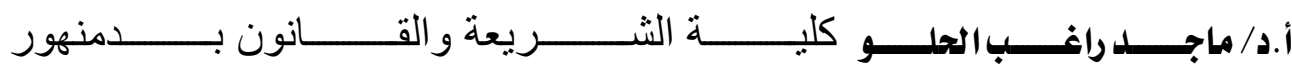




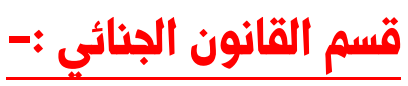

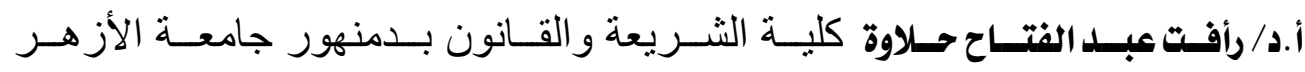

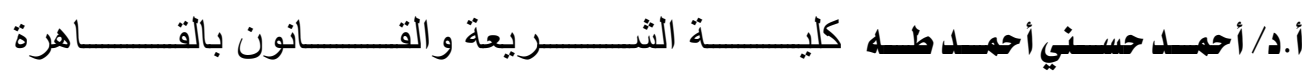

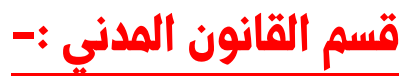

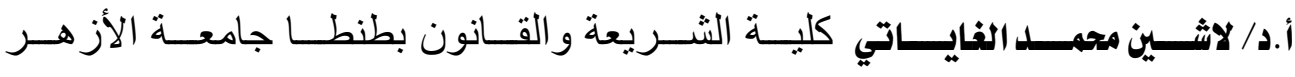

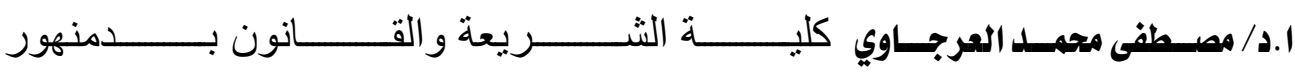

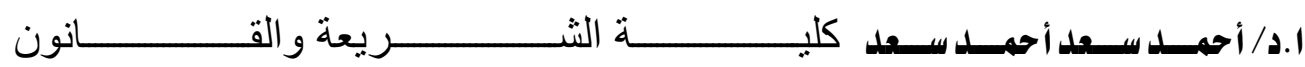

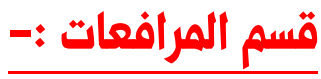

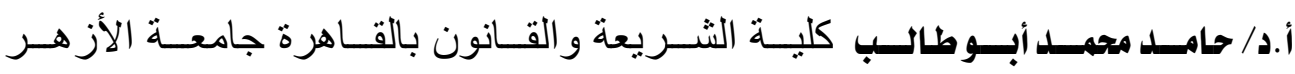

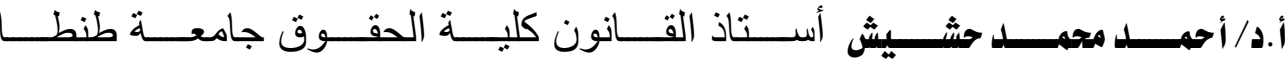

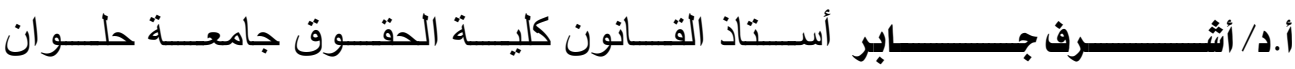

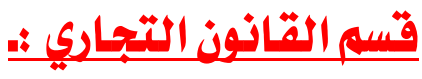

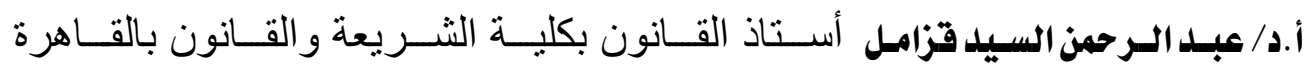

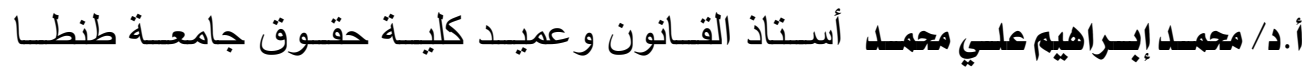

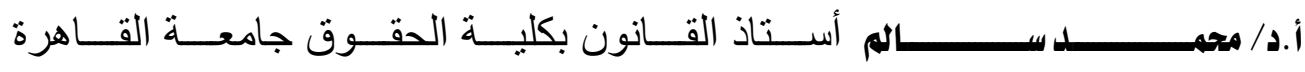




\section{ضوابط و شروط النشر في (ملجة :}

1 ـ جدارة الموضوع وجدية البحث و الإبداع فيه.

ץ ـ التزام المنهج العلمي المتبع في كتابة البحوث.

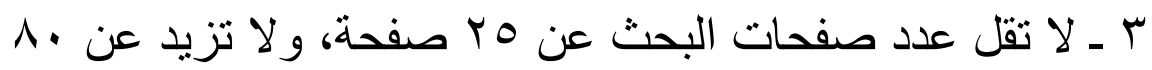

$$
\text { صفحة إلا لضرورة. }
$$

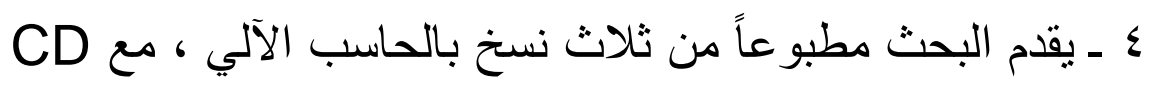
قبل التحكيم، ونسخة مطبوعة دع CD بعد التعديل و التصويب حسب رأي المحكمين.

ه ـ يراعى الالتزام بضوابط الطباعة المتعارف عليها بخصوص النشر في مثل هذه المجلات العلمية.

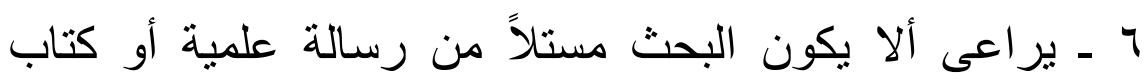
و ألا يكون قد سبق نشره بإحدى المجلات العلمية. 


\section{متويات العدد}

\begin{tabular}{|c|c|c|}
\hline \multicolumn{3}{|c|}{ أولاً : العقيدة والفلسفة } \\
\hline $1 \cdot \leq: 1 V$ & 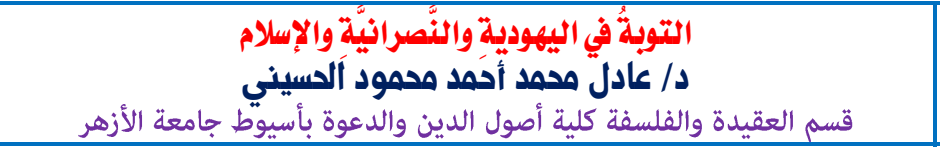 & 1 \\
\hline $1 \leq 7: 1.0$ & 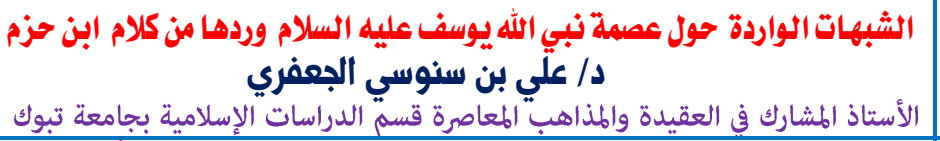 & $r$ \\
\hline YrA : IEV & 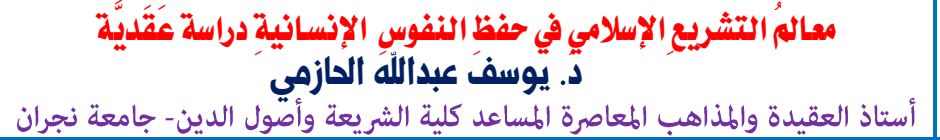 & $r$ \\
\hline$r_{1} \leqslant: r r q$ & 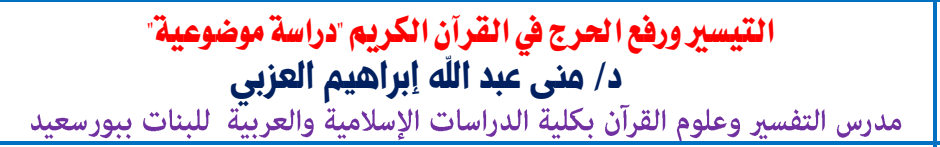 & $\varepsilon$ \\
\hline$r \leqslant \Lambda: M 10$ & 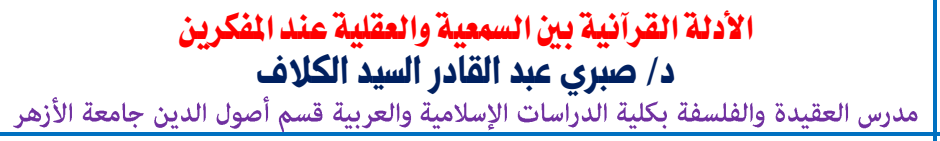 & 0 \\
\hline rᄉr: $r \leqslant q$ & 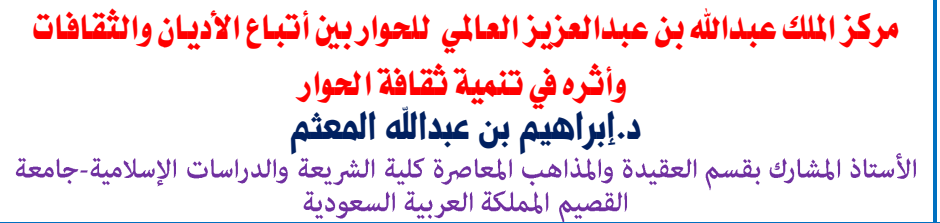 & 7 \\
\hline \multicolumn{3}{|c|}{ ثانيًا : التفسير وعلوم القرآن } \\
\hline$\varepsilon \varepsilon \wedge: \mu \wedge \mu$ & 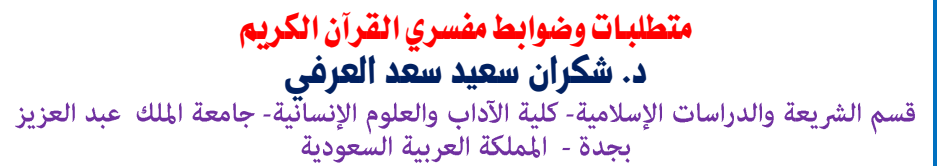 & $v$ \\
\hline \multicolumn{3}{|c|}{ ثالثا : الحديث وعلوهه } \\
\hline $01 \cdot: \leq \leqslant \leq 9$ & 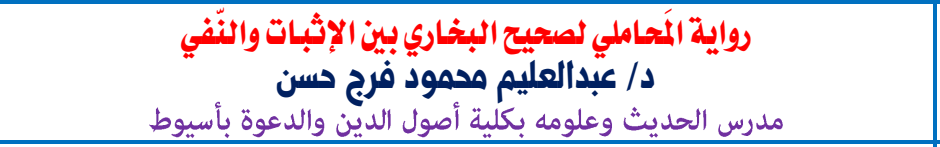 & $v$ \\
\hline $0\{.: 011$ & 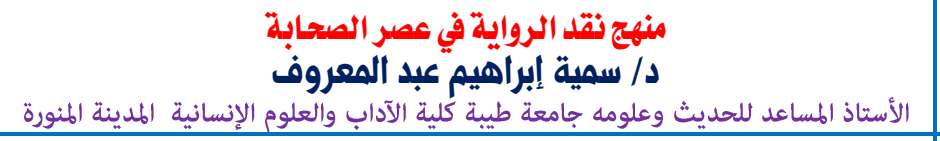 & $\wedge$ \\
\hline OAT: O & 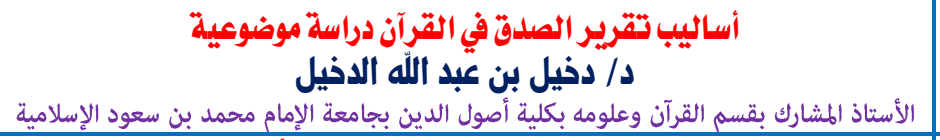 & 9 \\
\hline T) & 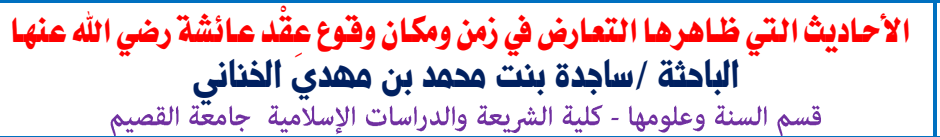 & $1 \cdot$ \\
\hline
\end{tabular}




\begin{tabular}{|c|c|c|}
\hline \multicolumn{3}{|c|}{ رابعًا : الدعوة والثقافة الإسلاصية } \\
\hline $771: 710$ & 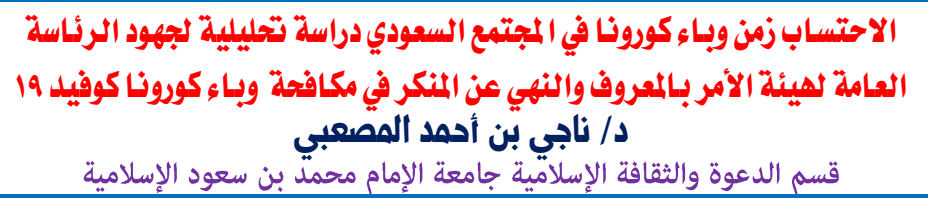 & 11 \\
\hline \multicolumn{3}{|c|}{ خاهسا : أصول الفقه } \\
\hline VY7: 779 & 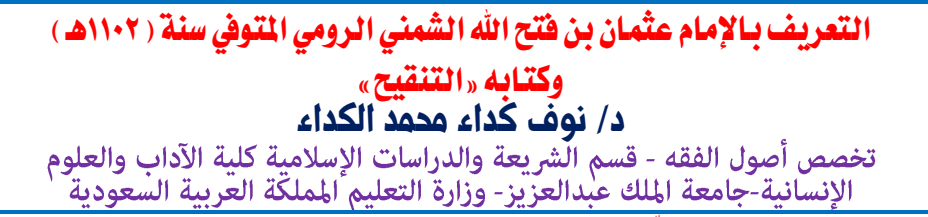 & ir \\
\hline$V T \leq: V Y V$ & 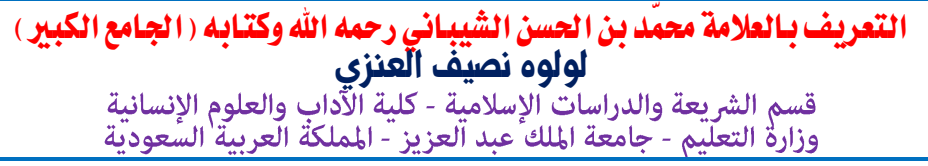 & ir \\
\hline 101 : V70 & 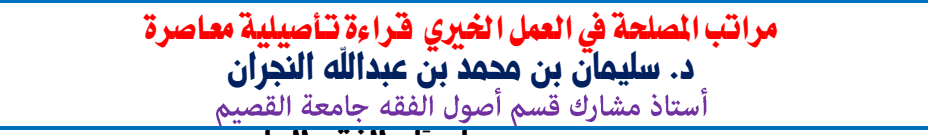 & $1 \varepsilon$ \\
\hline \multicolumn{3}{|c|}{ سادسا : الفمه العام } \\
\hline $911: 109$ & 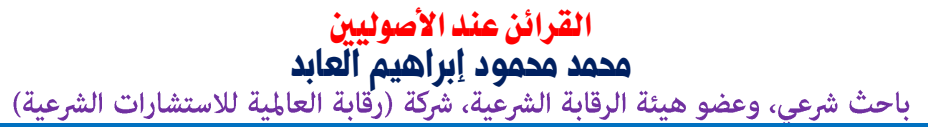 & 10 \\
\hline $9 \vee 7: 919$ & 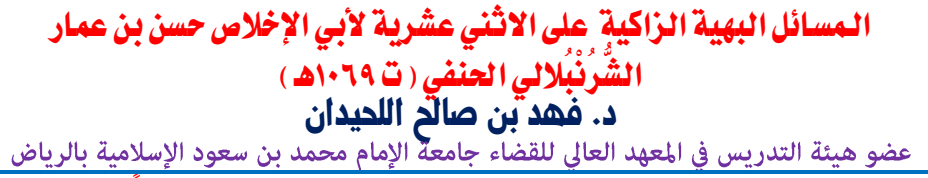 & 17 \\
\hline $1 . r \wedge: q V V$ & 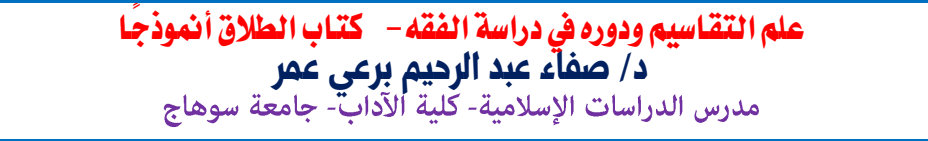 & iv \\
\hline $1.9 r: 1.49$ & 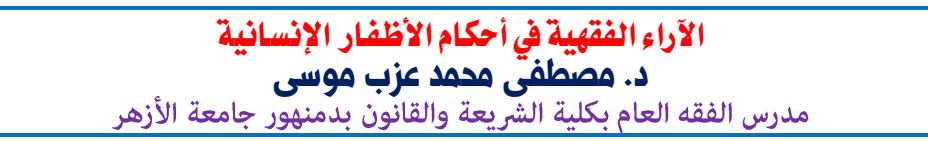 & $M$ \\
\hline $11 r \leq: 1.94$ & 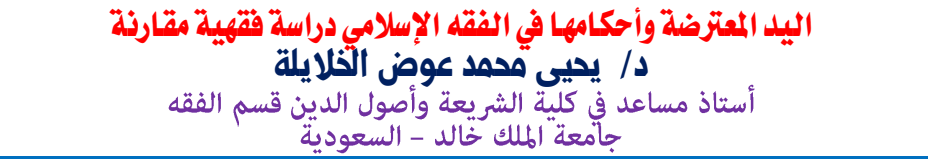 & 19 \\
\hline \multicolumn{3}{|c|}{ سابعا : الآدب والنقد } \\
\hline$\left|r_{1}\right|: 11 r_{0}$ & 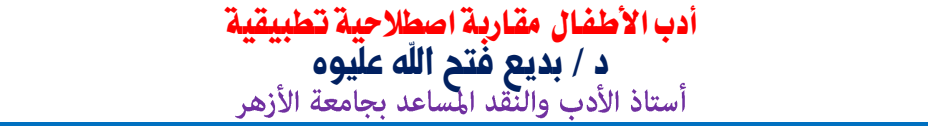 & $r \cdot$ \\
\hline 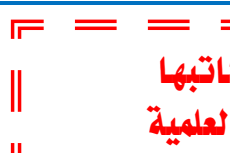 & 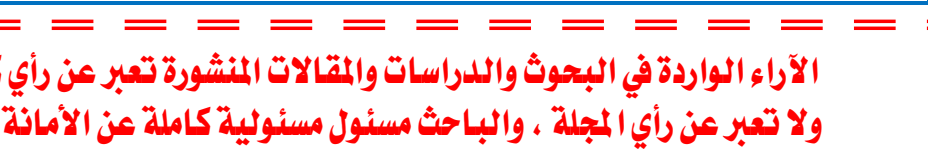 & ᄀ \\
\hline
\end{tabular}




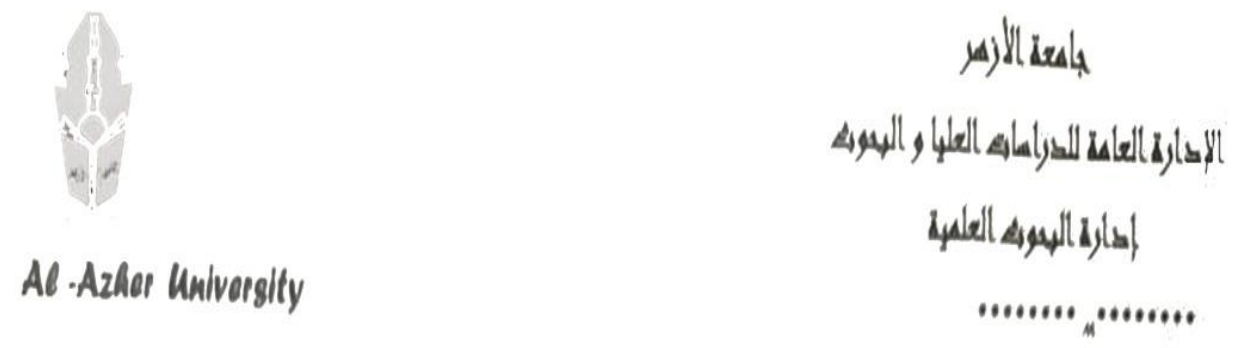

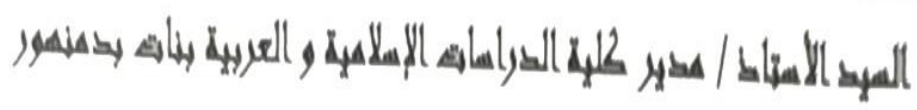

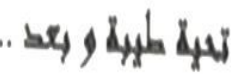

$* * * * * * * * * * * * * * * * * * * *$

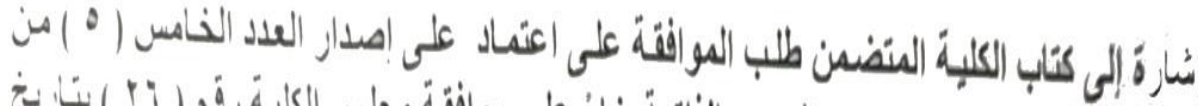

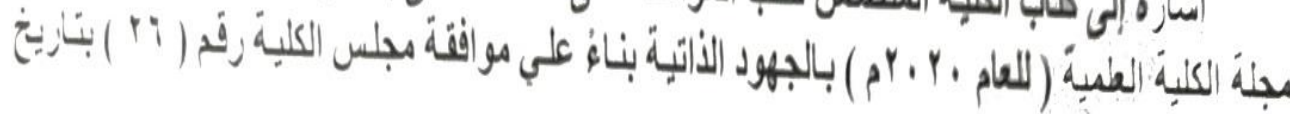

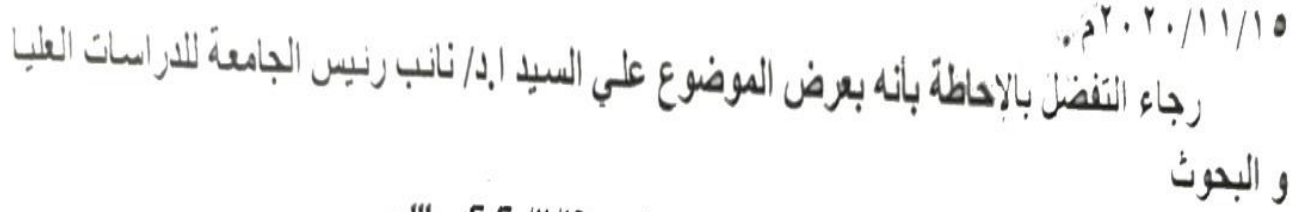

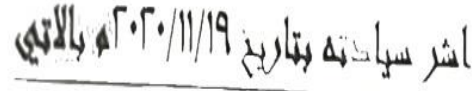

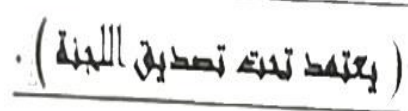

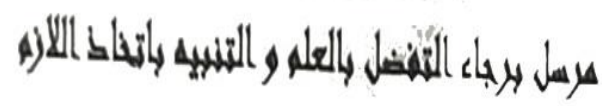

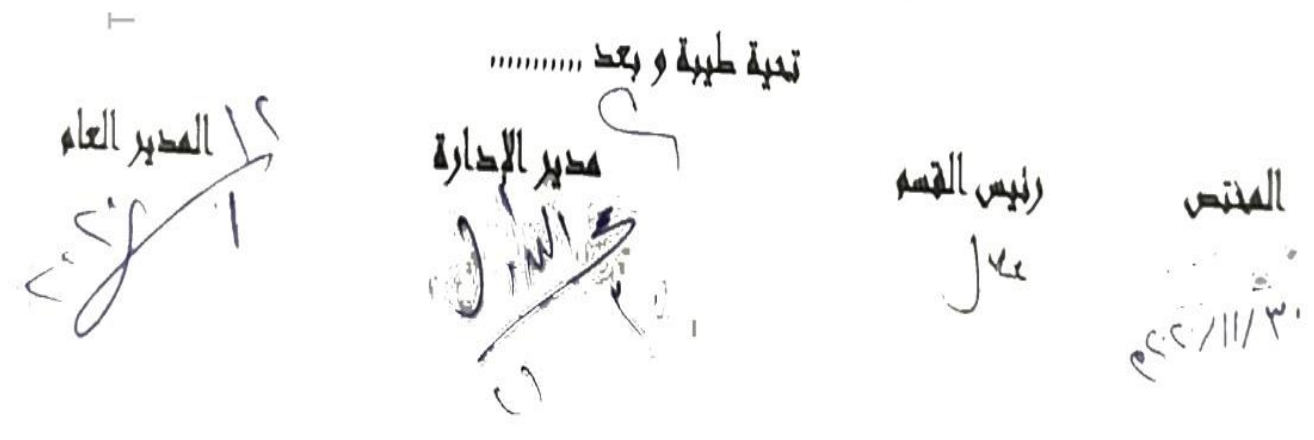




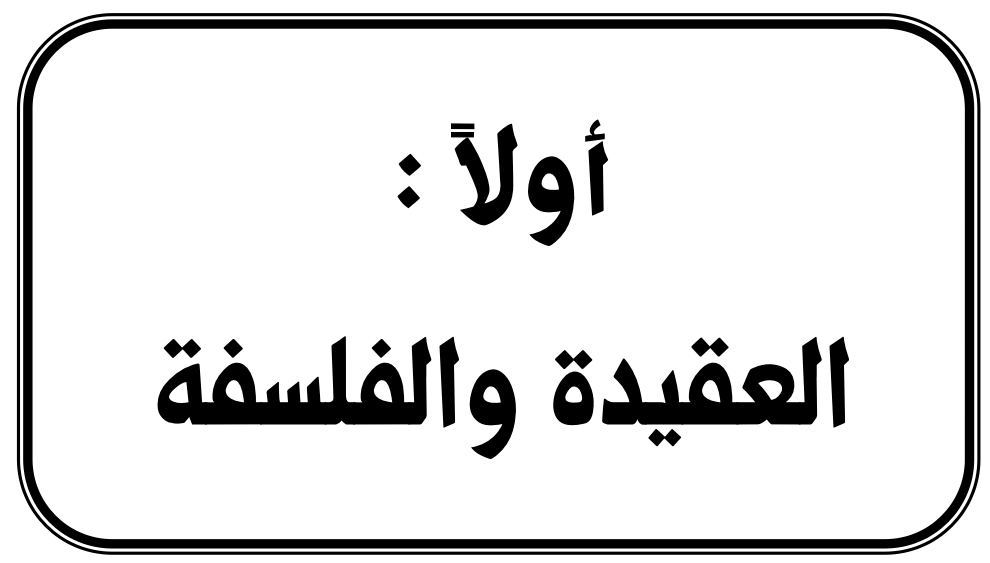


